\title{
Efficiency of Red Crescent Society Units in Gilan Province and Their Ranking using Data Envelopment Analysis
}

\author{
Karim Kia Kojouri ${ }^{1} \mathbb{D}$, Akbar Moradi Majd ${ }^{2} \mathbb{D}$, Abbas Sonaz $^{3,4} \mathbb{( D}$
}

Date of submission: 5 Feb. 2020 Date of acceptance: 26 Dec. 2020

\begin{abstract}
INTRODUCTION: Efficiency is one of the basic measures of organizational performance, and in general, refers to the degree or quality of the achievement of the desired goals. This study aimed to investigate the efficiency of Red Crescent population branches in Gilan province and rank them based on the data envelopment analysis model.

METHODS: This research was applied in terms of purpose and documentary in terms of implementation. For the purposes of the study, 16 branches of the Red Crescent Society in Gilan province were analyzed with GAMS software (version 24) in 2018. In this research, the inputoriented Banker, Charnes, and Cooper model was used as one of the basic models of data envelopment analysis to measure the relative efficiency of 16 branches of the Red Crescent Society in Gilan province. Afterward, the Anderson-Peterson super-efficiency model was used to rank the efficient units.

FINDINGS: Based on the findings, six branches, namely Astara, Rasht, Bandar Anzali, Tallish, Lahijan, and Sowme'eh Sara, had an efficiency score of one. In other words, they were recognized as efficient branches and could provide solutions and models as reference branches for inefficient branches to help them reach the efficiency limit. Afterward, the AndersonPeterson super-efficiency model was used to rank the efficient units. According to this model, the efficiency scores of the studied units were more than one and the Rasht branch had the highest efficiency.

CONCLUSION: The results provide researchers as well as branch managers and staff with suggestions that can help them make better decisions. An important point to keep in mind is that in order to increase the efficiency of a branch, it is necessary to reduce input costs and increase outputs based on reference branches. Due to the fact that this research uses an inputoriented approach, its purpose is to increase the indicators that enhance the efficiency of branches.
\end{abstract}

Original Article

Keywords: Data Envelopment Analysis; Efficiency; Organization; Ranking; Red Crescent Society.

How to cite this article: Kia Kojouri K, Moradi Majd A, Sonaz A. Efficiency of Red Crescent Society Units in Gilan Province and Their Ranking using Data Envelopment Analysis. Sci J Rescue Relief 2020; 12(3): 227-234.

\section{Introduction}

E fficiency in its general sense refers to the degree or quality of the achievement of the desired goals. Efficiency has also been defined as the ratio of outputs to inputs (1). Efficiency is the ratio of the utilization of an organization of its resources in production to its best performance at a point in time. Regarding the difference between efficiency and productivity, the following points should be considered: a) efficiency is expressed as a measure within the range of $0-1$, or in percentage, $0-100 \%$, while productivity can be greater than one; b) productivity is calculated in terms of various

1. PhD, Department of Management, Bandar Anzali Branch, Islamic Azad University, Bandar Anzali, Iran

2. PhD, Department of Mathematic, Bandar Anzali Branch, Islamic Azad University, Bandar Anzali, Iran

3. MSc, Public Administration, Bandar Anzali Branch, Islamic Azad University, Bandar Anzali, Iran

4. Research Center for Emergency and Disaster Resilience, Red Crescent Society of the Islamic Republic of Iran, Tehran, Iran Correspondence to: Abbas Sonaz, Email: abbassonaz17@gmail.com 
factors, such as workforce or capital productivity, while efficiency is a general measure that must be obtained from the combination of inputs and outputs (2).

Efficiency is one of the basic factors for the evaluation of organizational performance and simply shows the ratio of the output of an organization to its input. However, as the number of inputs and outputs increases, it becomes very difficult to measure the efficiency with this method. Accordingly, it is necessary to develop other methods for the assessment of efficiency (3).

Since the relationships between inputs and outputs and therefore the output function are unknown, we must estimate the relationships between them by an estimator to evaluate the performance of Decision-Making Units (DMUs). One of the estimators that can estimate the production function is Data Envelopment Analysis (DEA). The DEA is a non-parametric method based on mathematical programming. Data envelopment analysis divides homogeneous DMUs into two categories, namely efficient and inefficient units. Afterward, it considers efficient units as a reference for the improvement of the performance of inefficient units and makes a proposal to improve the inefficient units. This method was proposed in 1978 by Cooper, Charles, and Rhodes (4).

Goal of DEA is to identify the units that produce the most output from the least amount of inputs. In general, the purpose of DEA is to determine the limit of efficiency by which efficient and inefficient organizations can be distinguished from and compared with each other (5).

Nowadays, management experts emphasize the importance of performance evaluation models as one of the most valid indicators of organizational development. Therefore, currently, one of the main concerns of organizations is to achieve an efficient and flexible evaluation method that can examine all their functional aspects (6).

According to its international responsibilities (the International Committee of the Red Cross), the Red Crescent Society must provide assistance inside and outside the borders in times of crises, such as floods, earthquakes, and wars. Moreover, it has to raise awareness about crisis relief and management This Society, like other organizations, has specific establishments, articles of association, programs, and goals. Recently, a lot of research has been conducted on the nature and method of the evaluation of the performance of organizations. Results of this research are valuable since they allow us to understand the current state of organizations and examine future challenges in performance assessment.

Red Crescent Organization is responsible for the provision of relief; hence, attention should be paid to its promotion and development. Therefore, the present study aimed to increase the efficiency of the units of this organization in Gilan province. In studies based on statistical analysis, since the entire statistical population is not available, the data is mainly collected through sampling which is usually done by questionnaires. Afterward, the obtained data are analyzed using statistical methods. However, in the DEA method, the data are obtained through observation of the performance of the DMU and used along with mathematically proven models to estimate the production technology.

The estimated technology is always a subset of real technology; consequently, a unit that is inefficient in the estimated technology will always be inefficient in real technology as well. In the obtained technology, the units that are on the border of technology are considered efficient units, while the other ones are supposed to be inefficient. In Figure 1, units $\mathrm{A}, \mathrm{B}$, and $\mathrm{C}$ are efficient and unit $\mathrm{D}$ is inefficient.

Based on the built technology, efficient units can be considered as a reference for inefficient units. Therefore, inefficient units can be made efficient by reducing the inputs, increasing the outputs, or both, and moving the selected unit towards the technology border and obtaining an image point for it on the border. This image point is actually a suggestion to make the inefficient unit efficient. In Figure 1, by reducing the input of unit $\mathrm{D}$ to the image point, $\mathrm{D}^{*}$ is obtained on the 


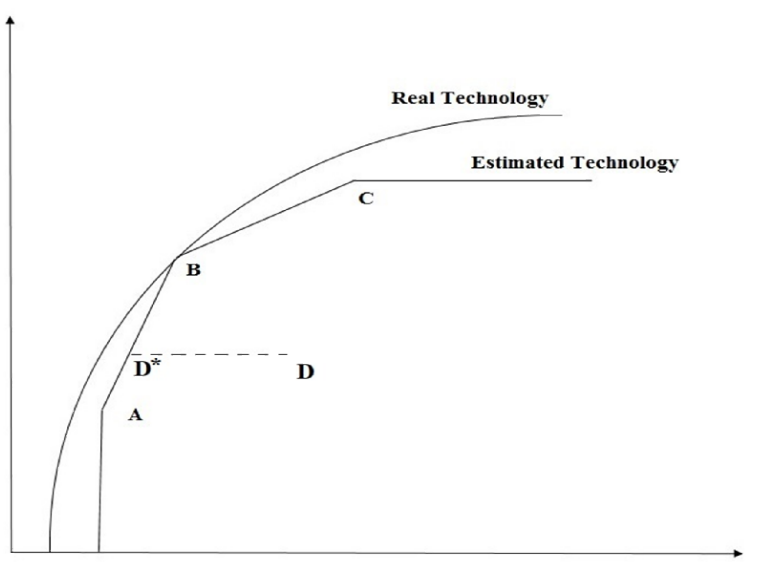

Figure 1. Real and estimated technologies in 2D mode border of the estimated technology which is efficient in this technology. Therefore, it can be considered as a proposal to make unit D efficient.

According to the above-mentioned factors and given the raised issues and extensive studies about performance evaluation, it was decided to use the non-parametric DEA technique to assess the efficiency of units. In this research, first, the inputs and outputs of the model were determined; afterward, one of the main DEA models was used to identify the efficient and inefficient units and find the cause. Subsequently, the units were ranked using the Anderson-Peterson (AP) superefficiency ranking methods. The main goal of the present study was to evaluate the efficiency of the Red Crescent branches in Gilan province and rank them accordingly.

Researchers have always used the DEA model to measure efficiency in many units and organizations. Consequently, several studies have been carried out in this regard some of the most important ones are as follows:

Guo et al. (2017) in a study entitled "Noncooperative two-stage network DEA model: linear vs. parametric linear" concluded that linear fractional non-cooperative network DEA models for two-stage network structures often turn into parametric linear models. They also found that when the parameters change, the converted parameter linear models are solved by the calculation of a series of linear models (7).

Powers and McMullen in their study conducted in 2017 used the DEA method with weight restrictions to differentiate strong performance criteria from other performance criteria in a set of securities to prevent the identification of the production units with undesirable levels that are about to achieve efficiency. They stated that the selection of securities can be an example of multicriteria decision-making issues that basically are made according to the examination of several indicators (8).

Xie in a study performed in 2016 calculated the cost-effectiveness of 107 property-liability insurance companies during 1993-2004 using the DEA technique. He considered workforce, business services, raw materials, and financial capitals of shareholders as the input and the current value of the damages and the real assets invested as the output of the model. Eventually, he concluded that the efficiency of the listed companies in the stock exchange is not worse than the efficiency, cost, and revenue change of private companies (9).

Bazrkar et al. in their study carried out in 2014 evaluated the net technical, scale, and combined performance of 454 insurance companies in 15 Eurozone countries using the DEA technique. They considered the total operation costs, total capital, total technical reserves, and total borrowing from creditors as input and the net income insurance premium and the total investment income as output (10).

Alikhani conducted a study in 2016 to determine the indicators that affected strategic performance management in the Red Crescent Society of Alborz province. For this purpose, he identified and evaluated the indicators that influenced the optimal performance of strategic management. He examined the current status of the system with a comprehensive look based on a balanced scorecard. He found that the mean of the components, namely learning and growth, internal processes and businesses, and finance and customer had significant effects on the strategic performance management, in that order (11).

Seddighi and Morovatti performed a study in 2014 entitled "Efficiency evaluation of road relief bases of Yazd province red crescent society in new year plan". They concluded that currently, due to the significant development of roads and the increase in the number of vehicles, it is necessary to provide road relief bases with better performance. Therefore, it is important to evaluate the performance of the road relief bases. For this purpose, they reviewed the performance of 13 road relief bases with the input-oriented Charnes, Cooper, and Rhodes model and ranked the bases accordingly (12). 


\section{Methods}

This research was applied in terms of purpose and documentary in terms of implementation since it describes a phenomenon. This research aimed to evaluate the efficiency of Red Crescent branches in Gilan province and rank them accordingly. Therefore, the DEA method was used which is a practical technique and is one of the most used methods in operations research. Through this method, the efficiency and performance of each unit can be evaluated by mathematical planning using forms and reports. In the following, we will first deal with the mathematical concepts and preliminaries of this matter:

Suppose we have $\mathrm{n}$ DMUs with $\mathrm{m}$ inputs and $\mathrm{s}$ outputs. In DEA, production technology is defined as follows:

Model 1: $\mathrm{T}=\left\{(\mathrm{x}, \mathrm{y}) \in \mathrm{R}_{+}^{\mathrm{m}} \times \mathrm{R}_{+}^{\mathrm{n}} \mid \mathrm{x}\right.$ can produce $\left.\mathrm{y}\right\}$

In model $1, \mathrm{x}$ is the input and $\mathrm{y}$ is the output of the DMUs. Main idea of achievement of efficiency in DEA is to compare DMUs with production technology. However, since the set of production possibilities is unknown to us the technology set is estimated using the collected observations. The set of production technology, or technology for short, is also called the set of production possibilities (4).

Suppose $D M U_{o}$ is the evaluated unit. In 1984, Banker, Charnes, and Cooper (BCC) introduced the $\mathrm{BCC}$ enveloping input-oriented model which is as follows (13):

$$
\begin{aligned}
& \min \theta \\
& \text { s.t. } \sum_{j=1}^{n} \lambda_{j} x_{i j} \leq \theta x_{i o} \quad i=1, \ldots, m \\
& \sum_{j=1}^{n} \lambda_{j} y_{r j} \geq y_{r o} \quad r=1, \ldots, s \\
& \sum_{j=1}^{n} \lambda_{j}=1
\end{aligned}
$$$$
\text { Model 2: } \quad \lambda_{j} \geq 0 \quad j=1, \ldots, n
$$

In model $\theta \leq 1$ is always true. In this model, $D M U_{o}$ is efficient if and only if $\theta^{*}=1$ and all auxiliary variables also equal 0 . The dual model of this model, known as the input-oriented BCC multiple-axis model, is as follows:

$$
\begin{array}{ll}
\max & \sum_{r=1}^{s} u_{r} y_{r o}+w \\
\text { s.t. } & \sum_{i=1}^{m} v_{i} x_{i o}=1 \\
& \sum_{r=1}^{s} u_{r} y_{r j}-\sum_{i=1}^{m} v_{i} x_{i j}+w \leq 0 \quad j=1, \ldots, n \\
& u_{r}, v_{i} \geq 0 \quad r=1, \ldots, s \quad, i=1, \ldots, m
\end{array}
$$

Model 3:

$$
w \text { free }
$$

In model 3 , if the optimal answer is 1 and $u^{*}>0, \mathrm{v}^{*}>0$, the $D M U_{o}$ is called strongly efficient (4) (14).

The Anderson-Peterson or super-efficiency model that makes it possible to determine the most efficient unit was proposed in 1993 by Anderson and Peterson for ranking the efficient units. This method is used to rank efficient units whose efficiency score is equal to one. In this method, the score of efficient units can be more than one, and thereby efficient units can be ranked similarly to inefficient units. The procedure is to remove the $D M U_{o}$ from the production possibility set and run the model for other DMUs. The higher the super-efficiency score of the unit, the more efficient that unit will be (4) (14). The super-efficiency model for the $D M U_{o}$ is as follows:

$$
\begin{aligned}
& \min \theta \\
& \text { s.t. } \sum_{j=1, j \neq o}^{n} \lambda_{j} x_{i j} \leq \theta x_{i o} \quad i=1, \ldots, m \\
& \sum_{j=1, j \neq o}^{n} \lambda_{j} y_{r j} \geq y_{r o} \quad r=1, \ldots, s \\
& \sum_{j=1}^{n} \lambda_{j}=1
\end{aligned}
$$$$
\text { Model 4: } \quad \lambda_{j} \geq 0 \quad j=1, \ldots, n
$$

In this research, since the used model is inputoriented, the goal is to help the inefficient units reach the efficiency limit through the maintenance of the output at a constant level and reduction of the input. Therefore, here, the type of the used function is MIN.

In this study, the data were collected from 16 branches of the Red Crescent Society in Gilan province with two inputs:

Training budget: $\mathrm{x}_{1}$

Operation budget: $\mathrm{x}_{2}$

And three outputs: 
Number of volunteers recruited: $\mathrm{y}_{1}$

Income of units: $\mathrm{y}_{2}$

Number of training courses: $y_{3}$

Which were collected in 2018 and have continued to operate continuously in the last four years (Table 1).

The raw data required for this research were extracted by referring to the deputies of the Red
Crescent Society of Gilan province. As mentioned earlier, each of these units is introduced as a DMU with two inputs and three outputs (Figure 2).

First, to determine the efficient and inefficient units and calculate the efficiency score of each DMU, the data was put in model 2. Results of the

Table 1. Data on inputs and outputs of the Data Envelopment Analysis model

\begin{tabular}{lcccccc} 
DMU & Branch & $\begin{array}{c}\text { Training budget } \\
\text { (Rial) }\end{array}$ & $\begin{array}{c}\text { Operation budget } \\
\text { (Rial) }\end{array}$ & $\begin{array}{c}\text { Recruited } \\
\text { volunteers }\end{array}$ & $\begin{array}{c}\text { Outcome } \\
\text { Income of } \\
\text { units }\end{array}$ & $\begin{array}{c}\text { Training } \\
\text { course }\end{array}$ \\
\cline { 2 - 6 } DMU1 & Astara & 97900000 & 625200000 & 796 & 1024726000 & 38 \\
DMU2 & Bandar Anzali & 81700000 & 731447000 & 1195 & 321300000 & 37 \\
DMU3 & Talish & 65000000 & 480200000 & 714 & 22050000 & 39 \\
DMU4 & Rasht & 163400000 & 691700000 & 828 & 1470308000 & 44 \\
DMU5 & Sowme'eh Sara & 105600000 & 719000000 & 1057 & 47970000 & 36 \\
DMU6 & Lahijan & 247500000 & 686250000 & 1817 & 2420500000 & 140 \\
DMU7 & Fuman & 55000000 & 468700000 & 510 & 50100000 & 18 \\
DMU8 & Langerud & 92000000 & 705500000 & 874 & 571580000 & 27 \\
DMU9 & Rudsar & 86400000 & 591200000 & 536 & 315160000 & 22 \\
DMU10 & Astaneh-ye Ashrafiyeh & 62500000 & 429700000 & 273 & 19900000 & 24 \\
DMU11 & Shaft & 7900000 & 322500000 & 470 & 17250000 & 32 \\
DMU12 & Rezvanshahr & 126500000 & 649200000 & 612 & 208519850 & 47 \\
DMU13 & Rudbar & 79200000 & 480200000 & 376 & 192919766 & 28 \\
DMU14 & Siahkal & 143600000 & 645500000 & 612 & 602550000 & 38 \\
DMU15 & Masal & 116000000 & 525200000 & 571 & 75935000 & 34 \\
DMU16 & Amlash & 95000000 & 383680000 & 523 & 8500000 & 30 \\
\hline
\end{tabular}

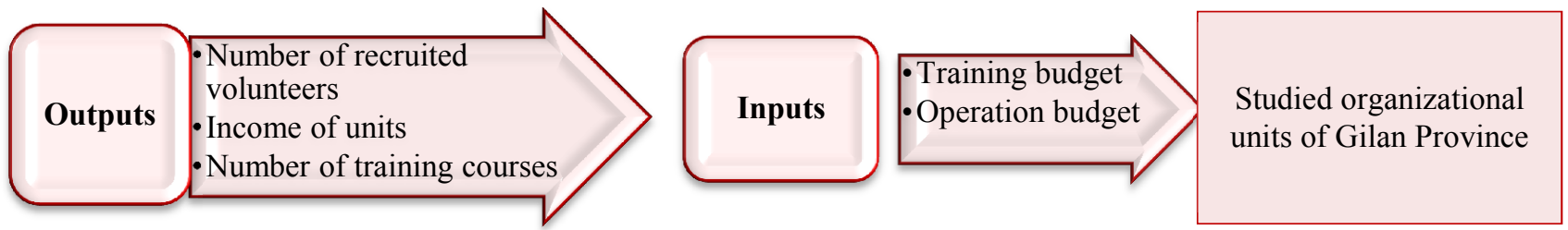

Figure 2. Decision-making units

performance of this model are summarized in Table 2. Subsequently, model 4 (super-efficiency model) was used to rank the efficient units. Results of the performance of this model are tabulated in Table 3. Furthermore, the data were analyzed in GAMS software (version 24). This software is able to perform optimization models in operations research.

Table 2. Results of the efficiency of Red Crescent decision making units or branches based on input-oriented Banker, Charnes, and Cooper model

\begin{tabular}{|c|c|c|c|c|c|}
\hline DMU & Branch & Efficiency score & DMU & Branch & Efficiency score \\
\hline 1 & Astara & 1 & 9 & Rudsar & 0.8404 \\
\hline 2 & Bandar Anzali & 1 & 10 & Astaneh-ye Ashrafiyeh & 0.8174 \\
\hline 3 & Talish & 1 & 11 & Shaft & 0.7993 \\
\hline 4 & Rasht & 1 & 12 & Rezvanshahr & 0.7580 \\
\hline 5 & Sowme'eh Sara & 1 & 13 & Rudbar & 0.7210 \\
\hline 6 & Lahijan & 1 & 14 & Siahkal & 0.6611 \\
\hline 7 & Fuman & 0.9634 & 15 & Masal & 0.5761 \\
\hline 8 & Langerud & 0.8802 & 16 & Amlash & 0.5622 \\
\hline
\end{tabular}




\section{Findings}

Results of using Model 2 on the data are shown in the second and fifth columns in Table 2. Given the efficiency score column in Table 2, it can be seen that out of the 16 evaluated branches, six branches, namely Astara, Rasht, Bandar Anzali, Talish, Lahijan, and Sowme'eh Sara have an efficiency score of one. Moreover, 10 other branches with an efficiency score of less than one are considered inefficient.

Furthermore, according to the second and fifth columns of Table 2, the rank of inefficient units according to their efficiency score are as follows: Fuman, Langerud, Rudsar, Astaneh-ye Ashrafieh, Shaft, Rezvanshahr, Rudbar, Siahkal, Masal, and

Table 3. Super efficiency scores of efficient units

\begin{tabular}{c|ccc}
\hline DMU & Branch & BCC* efficiency score & Super-efficiency score \\
\hline 4 & Rasht & 1 & 1.8966 \\
1 & Astara & 1 & 1.5609 \\
2 & Bandar Anzali & 1 & 1.4196 \\
6 & Lahijan & 1 & 1.3992 \\
3 & Talish & 1 & 1.3653 \\
5 & Sowme'eh Sara & 1 & 1.1024 \\
\hline
\end{tabular}

* Banker, Charnes, and Cooper

Table 4. Ranking of Red Crescent branches in Gilan province

\begin{tabular}{c|c|c|c|c|c|}
\hline DMU & Branch & Rank & DMU & Branch & Rank \\
\hline 4 & Rasht & 1 & 9 & Rudsar & 9 \\
1 & Astara & 2 & 10 & Astaneh-ye Ashrafiyeh & 10 \\
2 & Bandar Anzali & 3 & 11 & Shaft & 11 \\
6 & Lahijan & 4 & 12 & Rezvanshahr & 12 \\
3 & Talish & 5 & 13 & Rudbar & 13 \\
5 & Sowme'eh Sara & 6 & 14 & Siahkal & 14 \\
7 & Fuman & 7 & 15 & Masal & 15 \\
8 & Langerud & 8 & 16 & Amlash & 16 \\
\hline
\end{tabular}

Amlash. As can be seen, Fuman has the highest score among the inefficient units and is very close to the efficiency limit, while Amlash has the lowest efficiency score and is ranked last.

Based on the results, efficient branches are equal in terms of efficiency score. For this reason, to rank these units, it is necessary to use the superefficiency ranking technique in DEA that can rank efficient units (Table 2).

The AP super-efficiency model was used to rank the efficient units. The result of using Model 3 on the efficient units is shown in Table 3 .

Efficiency score of efficient units based on the input-oriented BCC model is shown in the third column of this table. Moreover, the superefficiency score of these units is shown in the fourth column. Based on these results, it can be concluded that the Rasht branch with a score of 1.8966 gained the first rank followed by the branches of Astara, Bandar Anzali, Lahijan, Talish, and Sowme'eh Sara. In other words, the efficient units with an efficiency score of one became distinguished from each other with the AP method. Based on this ranking, it is possible to compare the efficiency of the Red Crescent branches in Gilan province and evaluate them. The general results of this ranking are shown in Table 4.

Table 5 shows the reference units of each unit and it can be seen that the reference units of efficient units are themselves. However, the reference units of inefficient ones are efficient units. For example, for the inefficient unit of Shaft, the reference units are the Astara and Sowme'eh Sara branches.

Table 5. Reference units

\begin{tabular}{|c|c|cccc|}
\hline Column & Branch & Reference units & Column & Branch & Reference units \\
\hline 1 & Astara & Astara & 9 & Rudsar & Talish \\
2 & Bandar Anzali & Bandar Anzali & 10 & Astaneh-ye Ashrafiyeh & Sowme'eh Sara \\
\hline
\end{tabular}




\begin{tabular}{|c|c|c|c|c|c|}
\hline 3 & Talish & Talish & 11 & Shaft & Sowme'eh Sara, Astara \\
\hline 4 & Rasht & Rasht & 12 & Rezvanshahr & Lahijan \\
\hline 5 & Sowme'eh Sara & Sowme'eh Sara & 13 & Rudbar & Bandar Anzali, Rasht \\
\hline 6 & Lahijan & Lahijan & 14 & Siahkal & $\begin{array}{c}\text { Bandar Anzali, Rasht, } \\
\text { Lahijan }\end{array}$ \\
\hline 7 & Fuman & $\begin{array}{l}\text { Bandar Anzali, } \\
\text { Astara }\end{array}$ & 15 & Masal & Rasht, Talish, Astara \\
\hline 8 & Langerud & Rasht & 16 & Amlash & $\begin{array}{c}\text { Bandar Anzali, Sowme'eh } \\
\text { Sara }\end{array}$ \\
\hline
\end{tabular}

Table 6. Image points of inputs and outputs

\begin{tabular}{|c|c|c|c|c|c|c|c|c|c|c|c|}
\hline \multirow{3}{*}{ Column } & \multirow{3}{*}{ Branch } & \multicolumn{4}{|c|}{$\begin{array}{c}\text { Image points of the input with a } \\
\text { decreasing tendency }\end{array}$} & \multicolumn{6}{|c|}{ Image points of the output with an increasing tendency } \\
\hline & & \multicolumn{2}{|c|}{$\begin{array}{l}\text { Training budget } \\
\text { (Rial) }\end{array}$} & \multicolumn{2}{|c|}{$\begin{array}{l}\text { Operation budget } \\
\text { (Rial) }\end{array}$} & \multicolumn{2}{|c|}{$\begin{array}{l}\text { Number of } \\
\text { recruited volunteers }\end{array}$} & \multicolumn{2}{|c|}{$\begin{array}{l}\text { Income of branches } \\
\text { (thousand Rials) }\end{array}$} & \multicolumn{2}{|c|}{$\begin{array}{l}\text { Number of } \\
\text { training courses }\end{array}$} \\
\hline & & $\begin{array}{l}\text { Current } \\
\text { value }\end{array}$ & $\begin{array}{l}\text { Target } \\
\text { value }\end{array}$ & $\begin{array}{l}\text { Current } \\
\text { value }\end{array}$ & $\begin{array}{l}\text { Target } \\
\text { value }\end{array}$ & $\begin{array}{l}\text { Current } \\
\text { value }\end{array}$ & $\begin{array}{l}\text { Target } \\
\text { value }\end{array}$ & $\begin{array}{l}\text { Current } \\
\text { value }\end{array}$ & $\begin{array}{l}\text { Target } \\
\text { value }\end{array}$ & $\begin{array}{l}\text { Current } \\
\text { value }\end{array}$ & $\begin{array}{l}\text { Target } \\
\text { value }\end{array}$ \\
\hline 1 & Astara & 97900 & 97900 & 625200 & 625200 & 796 & 796 & 1024726 & 1024726 & 38 & 38 \\
\hline 2 & Astaneh-ye Ashrafiyeh & 81700 & 62600 & 731447 & 645500 & 1195 & 1302 & 321300 & 411100 & 37 & 45 \\
\hline 3 & Amlash & 65000 & 52900 & 480200 & 452311 & 714 & 900 & 22050 & 31170 & 39 & 49 \\
\hline 4 & Bandar Anzali & 163400 & 163400 & 691700 & 691700 & 828 & 828 & 1470308 & 1470308 & 44 & 44 \\
\hline 5 & Talesh & 105600 & 105600 & 719000 & 719000 & 1057 & 1057 & 47970 & 47970 & 36 & 36 \\
\hline 6 & Rasht & 247500 & 247500 & 686250 & 686200 & 1817 & 1817 & 2420500 & 2420500 & 140 & 140 \\
\hline 7 & Rezvanshahr & 55000 & 39250 & 468700 & 433200 & 510 & 816 & 50100 & 595710 & 18 & 31 \\
\hline 8 & Rudbar & 92000 & 84500 & 705500 & 599500 & 874 & 1002 & 571580 & 611720 & 27 & 39 \\
\hline 9 & Rudsar & 86400 & 59200 & 591200 & 507400 & 536 & 634 & 315160 & 426360 & 22 & 31 \\
\hline 10 & Siahkal & 62500 & 50100 & 429700 & 332000 & 273 & 550 & 19900 & 30900 & 24 & 41 \\
\hline 11 & Shaft & 79000 & 75800 & 322500 & 221500 & 470 & 800 & 17250 & 24410 & 32 & 50 \\
\hline 12 & Sowme'eh Sara & 126500 & 126500 & 649200 & 649200 & 612 & 612 & 208519.58 & 208519.58 & 47 & 47 \\
\hline 13 & Fuman & 79200 & 60540 & 480200 & 469600 & 376 & 421 & 192919.766 & 236000 & 28 & 34 \\
\hline 14 & Lahijan & 143600 & 143600 & 645500 & 645500 & 612 & 612 & 602550 & 601550 & 38 & 38 \\
\hline 15 & Langerud & 116000 & 93000 & 525200 & 460000 & 571 & 805 & 75935 & 99517 & 34 & 59 \\
\hline 16 & Masala & 95000 & 75500 & 383680 & 360000 & 523 & 960 & 8500 & 28650 & 30 & 46 \\
\hline
\end{tabular}

Table 6 summarizes the image points of inefficient units. In fact, these points indicate how much each of the inefficient units must change their inputs and outputs to become efficient. For example, in order to be efficient, the Rudbar unit must reduce its training cost from 92000 to 84500 thousand Rials and the operation costs from 705500 to 599500 thousand Rials. Besides, this unit should increase its recruited volunteers from 874 to 1002 , the branch income from 571580 to 611720 thousand Rials, and the training courses from 27 to 39 .

\section{Discussion and Conclusion}

The present study aimed to assess the efficiency and rank the Red Crescent branches in Gilan province and calculate the efficiency score of the branches which led to the identification of efficient units. In addition, it was found that each efficient branch could be introduced as a DMU for other inefficient branches. Therefore, one of the objectives of this study was to define values that can increase outputs, as shown in Table 6, in order to determine the image points of inputs and outputs to finally, increase efficiency.

The model inputs, namely training and operation costs are considered as debts in the financial statements of the branches; therefore, their reduction can increase the efficiency of the units. Accordingly, DEA can be used to find the numerical amount of the reduction of inputs through the determination of the image points. Based on the results of the method and formula of image points, it can be stated that inefficient branches should reduce their inputs and increase their outputs to achieve better efficiency.

According to the results obtained from the analysis of input and output data in GAMS software (version 24) and the DEA techniques, out of the 16 branches of the Red Crescent Society, six branches are efficient, and thereby can be DMUs for inefficient units. Moreover, image points provided solutions for each branch to improve their performance and increase their efficiency. 
Currently, awareness of the efficiency of the organization in order to achieve the goals and desired position of the organization is very important for managers. Role and importance of the Red Crescent Society as a service provider and relief organization are obvious. Therefore, the Red Crescent Society must always evaluate itself to increase its efficiency. Usage of the DEA model in this study made it possible to compare and rank the branches of the Red Crescent Society and provided solutions for the improvement of their efficiency and performance. In addition, relative efficiency, the cause of inefficiency of each branch, and the decisions needed to help inefficient units reach the limits of efficiency were determined. Moreover, it was clarified that each branch should use which unit as a reference.

Hence, due to the importance of the relief services, it is necessary to make an accurate and appropriate assessment of the efficiency of the Red Crescent Society branches to improve their performance and increase their efficiency. Besides, the assessment results can provide essential information for managers to develop their planning processes and achieve optimal resource allocation.

\section{Acknowledgments}

The authors would like to express their gratitude to the CEO, deputies, and staff of the Red Crescent Society of Gilan Province.

\section{Conflict of Interests}

Authors have no conflict of interests.

\section{References}

1. Malik M, Efendi S, Zarlis M. Data Envelopment Analysis (DEA) model in operation management. International Conference on Operational Research, Medan, Indonesia; 2018.

2. Mehregan MR. Data envelopment analysis: quantitative models for organizational performance evaluation. Tehran: Nashr-e-Ketabedaneshgahi;
2013. [In Persian].

3. Salehi SJ, Amiri M, Taghavifard MT, Razavi SH. Ranking of efficient units by using data envelopment analysis and analytical hierarchy process. Manag Knowl 2008; 81(21): 75-90. [In Persian].

4. Charnes A, Cooper WW, Rhodes E. Measuring the efficiency of decision-making units. Eur J Operat Res 1978; 2(6): 429-44.

5. Kutin N, Nguyen TT, Vallée T. Relative efficiencies of ASEAN container ports based on data envelopment analysis. Asian J Shipping Logistics 2017; 33(2): 67-77.

6. Casco B. Fuzzy interpretation. Trans: Ghaffari A, Maghsoudpour A. Tehran: Khajeh Nasir Toosi University of Technology; 2005. P. 1-338. [In Persian].

7. Guo C, Zhu J. Non-cooperative two-stage network DEA model: linear vs. parametric linear. Eur J Operat Res 2017; 258(1): 398-400.

8. Powers J, McMullen P. Using data envelopment analysis to select efficient large market cap securities. J Busin Manag 2000; 7(2): 31-42.

9. Xie X. Are publicly held firms less efficient? Evidence from the US property-liability insurance industry. J Bank Finan 2010; 34(7): 1549-63.

10. Bazrkar A, Khalilpour K. A comparative study on ranking the banks using Data Envelopment Analysis (DEA) and Stochastic Frontier Analysis (SFA) approach. Int Res J Appl Basic Sci 2013; 4(2): 302-6. [In Persian].

11. Alikhani T, Majidi M. Determining of factors influencing the strategic performance management in Alborz province Red Crescent society based on balanced scorecard. Sci J Rescue Relief 2017; 8(12): 134-43. [In Persian].

12. Seddighi H, Morovati Sharifabadi A. Efficiency evaluation of road relief bases of Yazd province Red Crescent society in New Year plan. J Rescue Relief 2013; 5(3): 18-26. [In Persian].

13. Banker RD, Charnes A, Cooper WW. Some models for estimating technical and scale inefficiencies in data envelopment analysis. Manag Sci 1984; 30(9): 1078-92.

14. Jahanshahloo GH, Lotfi FH, Nikoumaram H. Data envelopment analysis and its applications. Tehran: Asare Nafis; 2008. P. 1-225. [In Persian]. 